\title{
Commercial Vehicles in Delhi: Diesel Demand and Sulphur Emission
}

Debabrata Das, Indian Business Academy

\section{Abstract}

The aim of this paper is to estimate the future growth of commercial vehicles (passenger vehicles and goods vehicles) and to project the subsequent increase in diesel demand and the level of sulphur dioxide emissions in Delhi. Using an S-curve growth model on the data set of auto rickshaws, taxis, buses, and goods vehicles from 196566 to 2005-06, a long-term trend in the growth of commercial vehicles is projected to the year 2020-21. By 2020-21, the number of commercial vehicles is expected to increase to 0.51 million, with an increase in the share of goods vehicles and a simultaneous decrease in the share of passenger vehicles. The growth of commercial vehicles will boost the demand for diesel in 2020-21 by 68 percent, thus resulting in a threefold increase in sulphur dioxide emissions. The conversion of goods vehicle engines from diesel to CNG (compressed natural gas) will reduce diesel demand and sulphur dioxide levels significantly. A reduction of sulphur content in diesel can further reduce sulphur dioxide emissions.

\section{Introduction}

The transportation sector is the single largest contributor to air pollution, with motor vehicles being the worst polluters apart from most energy intensive modes of transport (Delhi Pollution Control Committee, Govt. of NCT of Delhi 2003). Considering only the energy directly consumed in vehicle operation, transporta- 
tion is the second largest user of commercial energy in India (Reddy et al. 2000). The energy for transportation comes primarily from petroleum products and, to a small extent, from electricity or other alternative sources. Air pollution by vehicle emissions causes the most hazardous environmental impact of the transport sector (Kathuria 2002). It is basically a product of road transport, which is the backbone of the urban transport system in most cities in India (Indian National Academy of Engineering 1996). Delhi, the capital, is spread over $1,483 \mathrm{sq} \mathrm{kms}$ with a population of 13.85 million as of the 2001 census. The transport system in Delhi is predominantly road-based, with railways catering to only about 1 percent of the local traffic. Buses are the primary mode of transport, which constitute only about 1 percent of total vehicles, whereas personal vehicles (two- and four-wheelers) account for 94 percent. The remaining five percent include goods vehicles, auto rickshaws, and taxis. Although the ratio of buses to total vehicles is far smaller than other modes, it caters to the highest percentage of the total traffic load. In comparison to other cities of India, the growth in total number of vehicles in Delhi is the largest (Planning Department, Govt. of NCT of Delhi 2007-08). This leads to higher energy consumption and air pollution. At present, Delhi has added 65.05 kilometers of mass rapid transit system (Metro rail). The expansion of this public transport system may reduce the growth of motor vehicles and, subsequently, fuel demand and air pollution (Das 2008).

The aim of this paper is to estimate the long-term trends in the growth of commercial vehicles (passenger vehicles and goods vehicles) and, subsequently based on the projected growth of vehicles, estimate the level and growth of energy demand and air pollution in Delhi. Using annual data for commercial vehicles from 1965-66 to 2005-06, the logistic and Gompertz models are appropriate for projection under the assumed saturation level. The best fit model is selected and used for projecting the level of vehicle growth on the basis of $R^{2}$ values, mean square error, and nature of the curve. These data account for four different types of commercial vehicles-auto rickshaws, taxis, buses, and goods vehicles. As a result of the growth in commercial vehicles, this paper projects the level and growth of diesel demand and sulphur dioxide emissions under different scenarios. The scenarios are business "as usual," substitution of alternative energy, and reduction of sulphur content in diesel.

The paper is organized into the following sections. In Section 2, the growth of commercial vehicles is analyed and models are developed that project this growth to the year 2020-21. Similarly, Section 3 analyzes the trend of diesel consumption 
and estimates the future demand under different scenarios. Sulphur dioxide emissions and future scenarios are discussed in Section 4. Section 5 provides strategies for reduction in diesel demand and sulphur dioxide emissions. The conclusion is in Section 6.

\section{Growth of Commercial Vehicles}

\section{Trends in the Growth of Commercial Vehicles}

Commercial vehicles have increased at an average rate of 7 percent per annum in Delhi (Table 1). From 1965-66 to 2005-06, the total number of motor vehicles increased more than sixty-fold, from 80 thousand to 4.8 million, while population rose about five-fold, 3.1 million to 16 million. Of total vehicles, the share of commercial vehicles is far less than personal vehicles. Commercial vehicles consist of passenger vehicles (auto rickshaw, taxi, bus) and goods vehicles. The average growth rate of goods vehicles is higher than that of passenger vehicles. In absolute terms, the number of passenger vehicles increased from 10.5 thousand to 137.8 thousand from 1965-66 to 2005-06, while goods vehicles increased from 7 thousand to 142 thousand during the same period. In the category of passenger vehicles, the share of auto rickshaws is more than that of taxis and buses. However, the average annual growth rate of buses is highest (7.6\%), followed by auto rickshaws (6.6\%) and taxis (4.7\%). The low demand for taxis may be due to the higher cost of travel compared to auto rickshaws.

Although the growth rate of buses is highest, their share of total vehicles has gradually decreased from 1.76 percent in 1965-66 to about 1 percent in 2005-06. This is basically due to the enormous growth in the number of personal vehicles. Buses cater to 60 percent of the total traffic load, whereas personal vehicles account for 94 percent of total vehicles but cater to only 30 percent of the total traffic load (Planning Department Govt. of NCT of Delhi 2005-06). Interestingly, the period between 2000-01 and 2005-06 shows an average negative growth rate for all categories of vehicles. The negative growth rate is significantly higher in the case of passenger vehicles $(-8.77 \%)$ compared to goods vehicle $(-2.31 \%)$. Similarly, in the category of passenger vehicles, auto rickshaws have registered the highest negative average growth rate $(-8.71 \%)$, followed by buses $(-4.58 \%)$ and taxis $(-2.06 \%)$. This is due to the implementation of several directives issued by the Supreme Court of India for control of vehicular pollution in the years 1998, 2000, and 2001. These directives include phasing out or banning the plying of old commercial passenger vehicles and requiring the conversion of commercial passenger vehicles to a single 


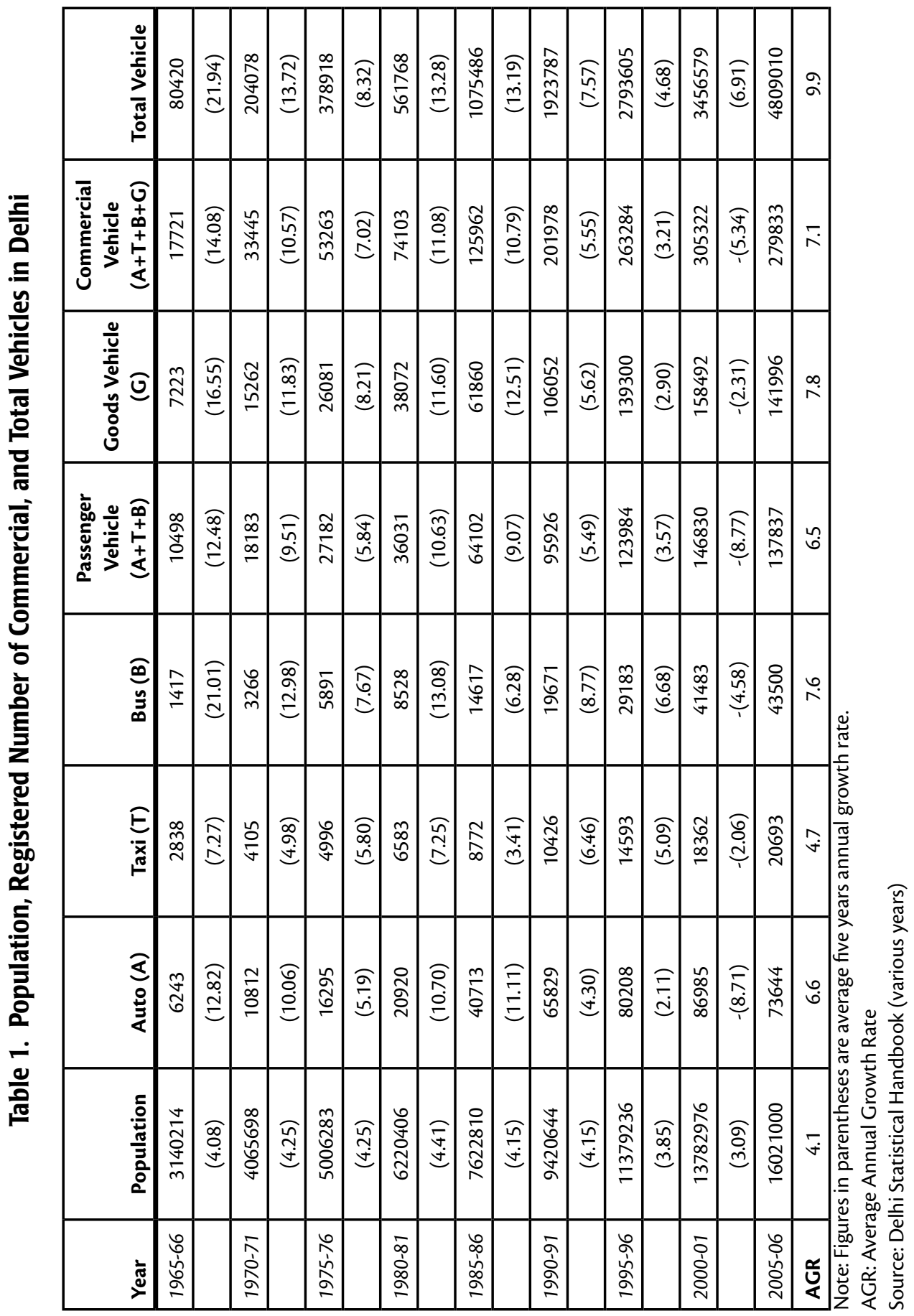


fuel mode, CNG (Transport Dept. Govt. of NCT of Delhi 2000). In spite of negative growth in the recent past, commercial vehicles have increased significantly over the years in Delhi (Table 1). In what follows, using the trend of vehicle ownership per 100 persons, forecasting models of commercial vehicle growth are developed.

\section{Model for Forecasting of Commercial Vehicles}

The growth in commercial vehicles per 100 persons over time typically follows a sigmoid or S-shaped curve. There are a number of different functional forms that can describe S-shaped curves, for example, logistic, Gompertz, Von Bertalanffy, etc. (Draper and Smith 1998). These curves forecast how and when a given growth system will reach its saturation limit. Gompertz and logistic functions are developed in reaction to Malthus' natural growth function, in which the population grows exponentially, which seems to be unrealistic because environment imposes limitations on every growth pattern. Gompertz' original work was presented at the Royal Society of London in 1825 and is described in the literature of Smith and Keyfitz (1977). However, a logistic model was applied for the first time by Verhulst, who published his research in 1838 in the journal Correspondence Mathematique et Physique. Almost a century later, in 1920, Pearl and Reed rediscovered the logistic model in the course of their study of the evolution of fly populations (Jarnc et al. 2005). Originally, these models were developed to describe the self-limiting growth of population. First use of these models to analyze economic growth is attributed to the French sociologist Gabriel Tarde (Tarde 1903). Tarde's idea, followed by other scholars such as Prescott (1922), obtained demand forecasts for the automobile using the Gompertz function. Although the path of these growth functions can be represented in the general S-shape fashion, different types of entities can grow different patterns. Hence, the exact form of the curves, including the slope and the asymptote, may be different for each particular growth pattern. For example, the slope may be very steep during early phases, including rapid growth, or it may be gradual, suggesting a slow and hesitant start, but all of them will level to the saturation limit. The main advantage of these models is to reach the saturation level in the long-term forecast, as most of the systems, whether natural or artificial, attain the saturation level after a certain period. The properties of the S-curve growth model are such that if the growth is quite rapid at an early phase and relatively slow when approaching the saturation level, then the Gompertz function is the best method because it attains its maximum rate of growth at an earlier phase than that of the logistic model. If, on the other hand, the diffusion process is such that growth is initially slow and relatively rapid during the maturing phases, then the logistic model is a superior forecasting method because 
it grows more rapidly towards the maximum level than the Gompertz model. The two frequently-used functional forms of S-curve representing different growth patterns are the logistic and the Gompertz functions (Ogut 2004; Singh 2006).

An important issue in implementation of these models is the estimation of saturation levels. A few studies have estimated the saturation level from the S-curve growth function (Singh 2000), but most of the studies provide the saturation level externally by applying a rule of thumb, e.g., one car per family (Palelink 1960), one driving member per family (Tanner 1978), per capita vehicle ownership (Button et al. 1993; Peter et al. 2003). In this paper, the seating capacity of a commercial passenger vehicle is assumed to be the saturation level. The seating capacities of auto rickshaws and taxis are 3 and 5, which implies that the saturation levels per 100 persons is assumed to be 33 and 20, respectively. However, the seating capacity of buses ranges from 11 (RTV) to 60 (high-capacity bus). Therefore, it was assumed that the saturation level for buses is 2 for 100 persons. In the case of goods vehicles, the saturation level is assumed to be 4 per 100 persons. The assumption is based on the growth-size (G-s) relationship (Pelsmacker 1990). The idea behind this approach is that at the saturation level, the relative growth rate is equal to zero. The growth of goods vehicles $(G)$ has a linear relationship with per capita goods vehicles $(s)$. The best fit linear function is obtained as $G=-6.13+149.48 \mathrm{~s}$, which is significant at the $95 \%$ confidence level. At the saturation limit, i.e., $G=0$, this implies the number of per capita goods vehicles $(s)=0.04$. Then, using the saturation level $(S)$, models have been developed based on logistic and Gompertz distributions to forecast commercial vehicle $(V)$ growth per 100 persons with respect to time $(t)$ in Delhi.

Logistic Model: The change in vehicle growth with respect to time, i.e., $\left(\frac{d V_{t}}{d t}\right)$, is proportional to the product of the level of vehicle growth at time, $t$ i.e., $\left(V_{t}\right)$, and the fraction of market untapped, i.e., $\left(\frac{S-V_{t}}{S}\right)$, where $S$ is the saturation limit of the growth (Das et al. 2009). The corresponding differential equation is

$$
\frac{d V_{t}}{d t}=\frac{b V_{t}\left(S-V_{t}\right)}{S}
$$

where $b>0$ is the proportionality constant, i.e., growth rate. 
Integrating the above differential equation over interval 0 to $t$, the logistic function is

$$
V_{0}=\frac{S}{1+a}
$$

The parameters $a$ and $b$ model the location and shape of the curve, respectively. For $t=0, V_{0}=\frac{S}{1+a}$ is the starting level of automobile growth, and for $t=$ very large, $V_{\infty}=S$ is the saturation limit. The logistic curve reaches its maximum growth rate at half of the saturation level, i.e., $V_{t}=S / 2$, called the point of inflection of the curve, and occurs at $t=\frac{\ln a}{b}$. The logistic curve is symmetric about the point of inflection.

Gompertz Model: The change in vehicle growth with respect to time, i.e., $\left(\frac{d V_{t}}{d t}\right)$, is proportional to the product of the present level of vehicle growth at time $t$, i.e., $\left(V_{t}\right)$, and the logarithm of vehicle density level, i.e., $\ln \left(\frac{S}{V_{t}}\right)$, where $S$ is the saturation limit of the growth (Das et al. 2009). The corresponding differential equation is

$$
\frac{d V_{t}}{d t}=b V_{t} \ln \left(\frac{S}{V_{t}}\right)
$$

where $b>0$ is the proportionality constant, i.e., growth rate.

Integrating the above differential equation over interval 0 to $t$, the Gompertz function is

$$
V_{t}=S e^{-a e^{-b t}}
$$

The parameters $a$ and $b$ model the location and shape of the curve, respectively. The Gompertz curve reaches its maximum growth rate at $V_{t}=S / e$, which is the point of inflection of the curve that occurs at $t=\frac{\ln a}{b}$. For $t=0, V_{0}=S e^{-a}$, is the 
starting level of vehicle growth, and for $t=$ very large, $V_{\infty}=S$ is the saturation limit. Unlike the logistic curve, it is not symmetrical about its point of inflection.

Finally, using saturation level $S$ and time variable $t$, the parameters $a$ and $b$ are estimated by an ordinary least squares procedure after transforming the logistic (equation [2]) and Gompertz (equation [4]) models into logarithmic form,

$$
\begin{aligned}
& \ln \left(\frac{S}{V_{t}}-1\right)=\ln a-b t \\
& \ln \left[\ln \left(\frac{S}{V_{t}}\right)\right]=\ln a-b t
\end{aligned}
$$

where time variable $t$ is taken as 1 for 1965-66, 2 for 1966-67, ....... and 41 for 2005-06. The ordinary least squares estimation is carried out using Excel. Based on $\mathrm{R}^{2}$ value and mean square error (MSE), the better-forecasted values are selected, where MSE is the average of square of the difference between actual and forecasted values.

\section{Model Estimation}

The estimated results of auto rickshaws, taxis, buses, and goods vehicles in both these models are shown in Table 2. Although the models have different functional forms, they have several features in common. All of them increase monotonically and have horizontal asymptotes, with one of them representing the saturation level.

As per $\mathrm{R}^{2}$ values, the models fit the data very well. However, the $\mathrm{R}^{2}$ value of taxis in both these models is low. All the parameters have the expected sign, and most are highly significant, as can be observed from $t$ statistics. The highest $R^{2}$ and lowest MSE values of buses and goods vehicles are found in the Gompertz model. Similarly, the growth in auto rickshaw provides higher $\mathrm{R}^{2}$ in the logistic model. However, taxis has same $\mathrm{R}^{2}$ in both these modes. The properties of these models are also in Figures 1, 2, 3, and 4, respectively. 
Table 2. Estimated Parameters of Logistic and Gompertz Models

\begin{tabular}{lcrrrr}
\hline Models & Parameters & \multicolumn{1}{c}{ Auto } & \multicolumn{1}{c}{ Taxi } & \multicolumn{1}{c}{ Bus } & Goods Vehicle \\
\hline & $\mathrm{b}$ & 0.0094 & 0.0066 & 0.0275 & 0.0328 \\
Logistic & & $(6.85)$ & $(3.83)$ & $(9.99)$ & $(12.51)$ \\
& $\mathrm{a}$ & 107.8440 & 202.9676 & 20.3391 & 18.2503 \\
& & $(43.95)$ & $(110.64)$ & $(35.67)$ & $(32.51)$ \\
& $\mathrm{R}^{2}$ & 0.55 & 0.28 & 0.72 & 0.80 \\
& $\mathrm{MSE}$ & 0.0317 & 0.0002 & 0.0021 & 0.1123 \\
& $\mathrm{~b}$ & 0.0025 & 0.0013 & 0.0116 & 0.0139 \\
Gompertz & & $(6.67)$ & $(3.93)$ & $(10.02)$ & $(12.60)$ \\
& $\mathrm{a}$ & 4.7267 & 5.3200 & 3.1528 & 2.9920 \\
& & $(77.15)$ & $(223.75)$ & $(37.28)$ & $(29.39)$ \\
& $\mathrm{R}$ & 0.54 & 0.28 & 0.72 & 0.81 \\
& $\mathrm{R}$ & 0.0301 & 0.0002 & 0.0019 & 0.0276 \\
\hline
\end{tabular}

Note: Figures in parentheses are values of $t$-statistics.

Note: Italics figures are selected parameters.

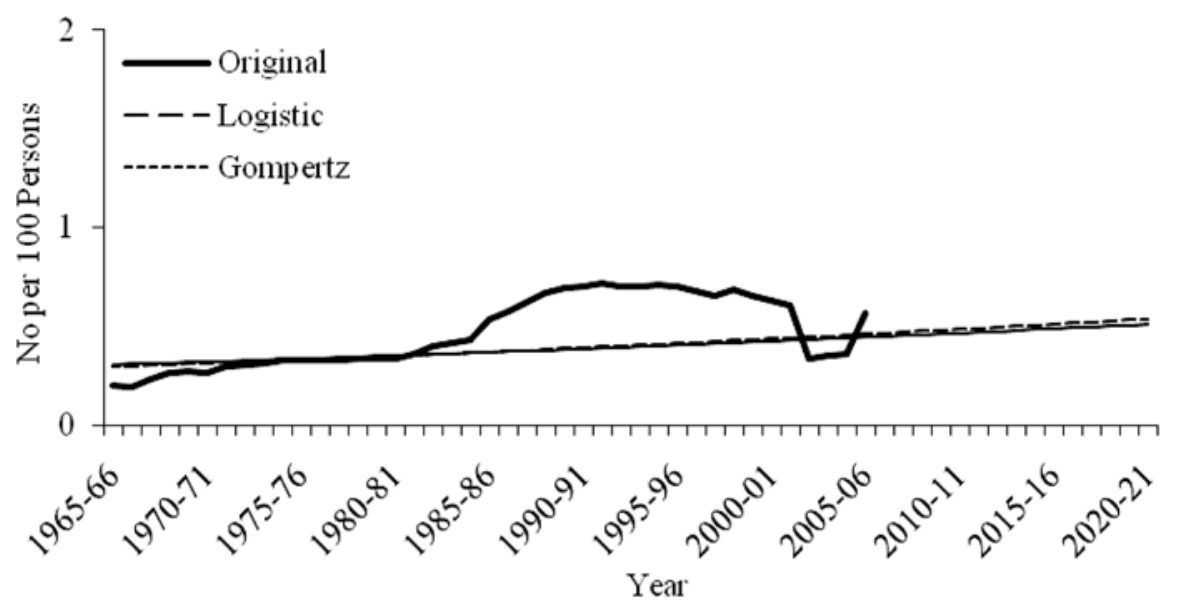

Figure 1. Auto Rickshaw Growth

In Figures 1 and 2, the original growth curve of auto rickshaws and taxis are initially slow, then increases and decreases rapidly before taking an upward direction. Therefore, the trend of the original curve seems to follow the logistic path. This decrease in growth after 2001-02 is due to the intervention of the Indian government's auto fuel policy. 


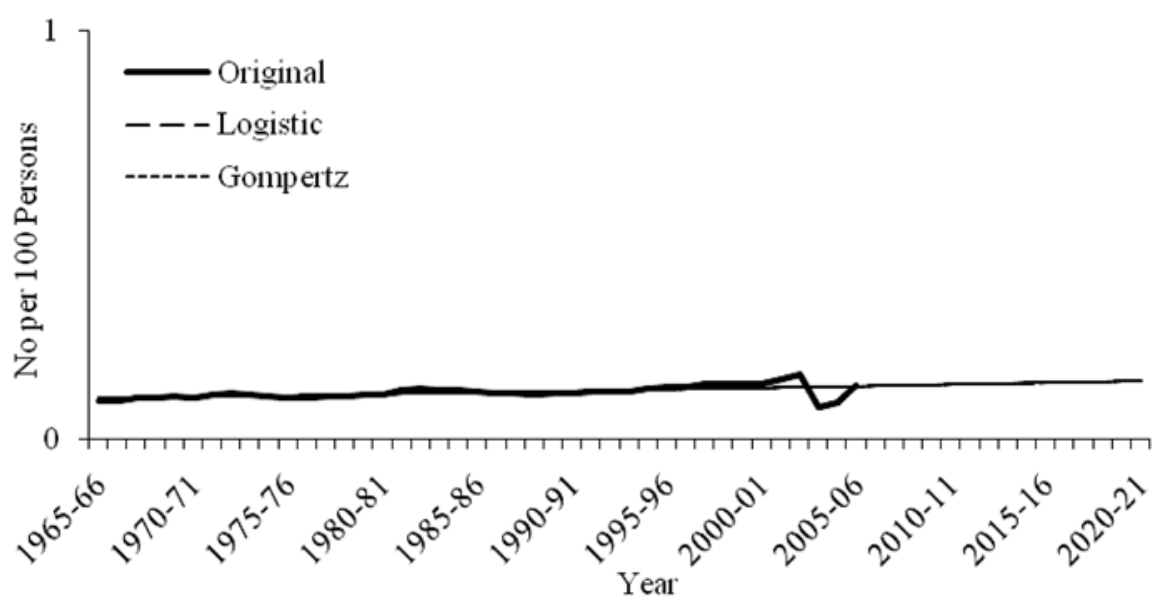

Figure 2. Taxi Growth

The slow growth of taxis make the logistic and Gompertz curves linear, by appearance, but it is really not so. Therefore, from the figure, it is difficult to identify the curve that follows the original curve.

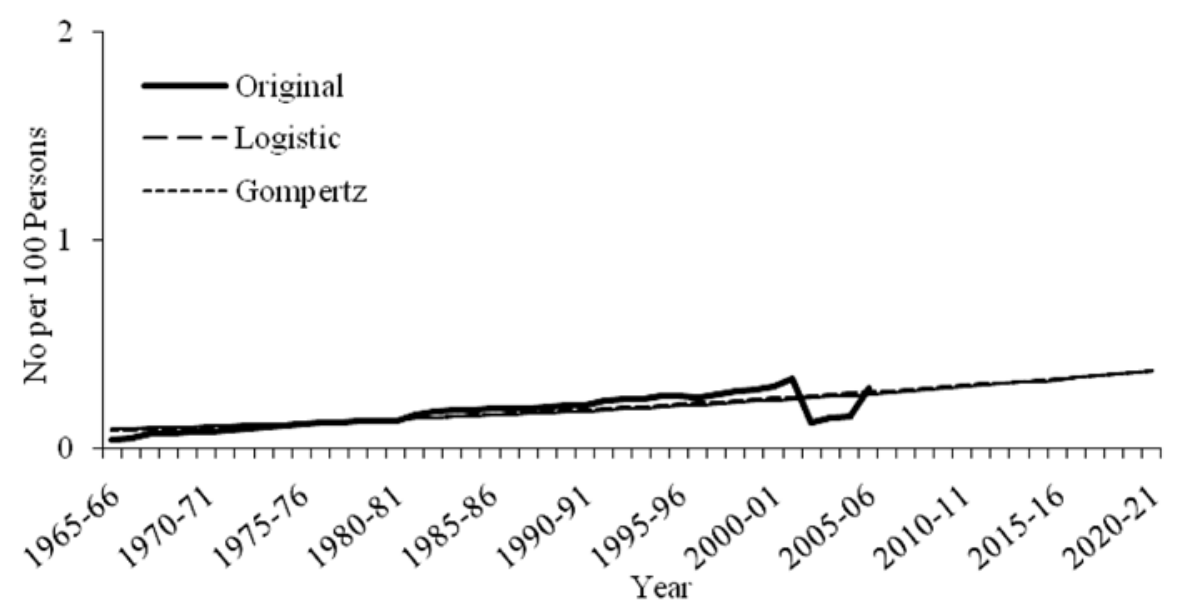

Figure 3. Bus Growth

The original growth of buses (Figure 3 ) and goods vehicles (Figure 4) is quite rapid at an early phase. Hence, the original growth takes the shape of the Gompertz curve. 


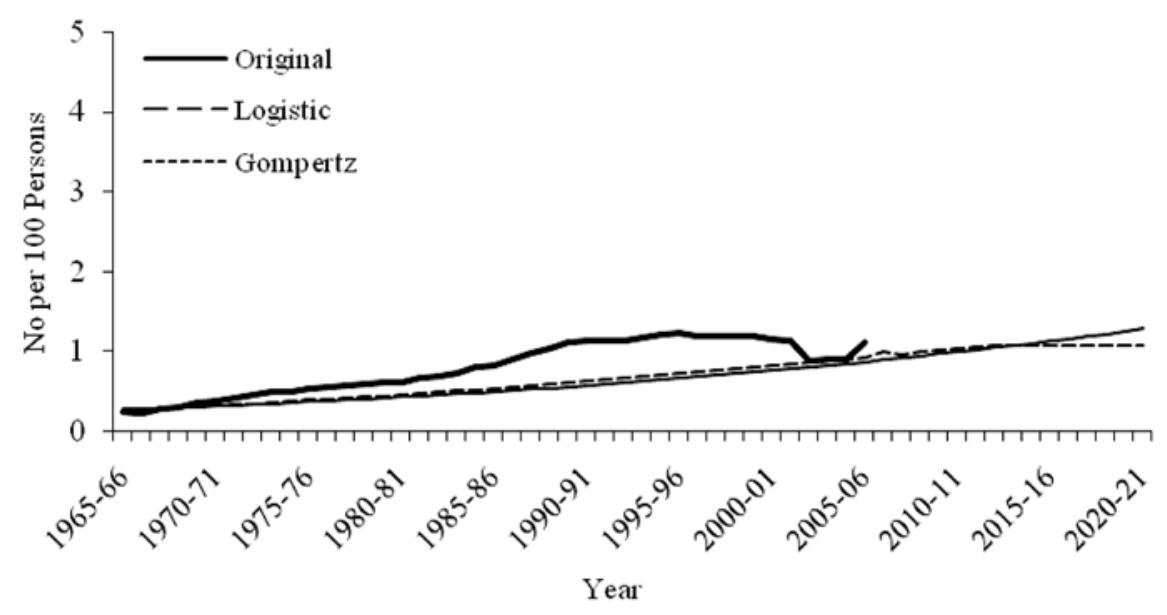

Figure 4. Goods Vehicle Growth

Therefore, as per $\mathrm{R}^{2}$ value, MSE, and properties of the curves, the logistic model fits the data better in projecting the growth of auto rickshaws and taxis, whereas the Gompertz model fits better in projecting the growth of buses and goods vehicles. The saturation level and selected parameters $a$ and $b$ in Table 2 help to develop forecasting models for the growth of different motor vehicles per 100 persons as given bellow:

$$
\begin{aligned}
& \text { Autorickshaw }_{t}=\frac{33}{1+107.8440 e^{-0.0094 t}} \\
& \text { Taxi }_{t}=\frac{20}{1+202.9676 e^{-0.0066 t}} \\
& \text { Bus }_{t}=2 e^{-3.1528 e^{-0.0112 t}} \\
& \text { Goodsvehicle }_{t}=4 e^{-2.9920 e^{-0.0139 t}}
\end{aligned}
$$

\section{Growth Projection of Commercial Vehicles by 2020-21}

Substituting $t=46,51$, and 56 in equations (7), (8), (9) and (10), the projected level of auto rickshaws, taxis, buses, and goods vehicles per 100 persons for the years 
2010-11, 2015-16 and 2020-21 are determined. This projected level of commercial vehicles per 100 persons is converted into an absolute number by multiplying the projected population and dividing it by 100 , as reported in Table 3 .

Table 3. Projected Growth of Commercial Vehicles in Delhi

\begin{tabular}{|l|c|c|c|c|c|c|c|}
\hline Year & Population & $\begin{array}{c}\text { Auto } \\
\text { Rickshaw } \\
(\mathbf{A})\end{array}$ & Taxi (T) & Bus (B) & $\begin{array}{c}\text { Passenger } \\
\text { Vehicle } \\
(\mathbf{A + T + B})\end{array}$ & $\begin{array}{c}\text { Goods } \\
\text { Vehicle } \\
(\mathbf{G})\end{array}$ & $\begin{array}{c}\text { Commer- } \\
\text { cial Vehicle } \\
(\mathbf{A + T + B + G})\end{array}$ \\
\hline $2005-06^{*}$ & $16,021,000$ & 73644 & 20693 & 43500 & 137837 & 141996 & 279833 \\
\hline & & $(53.43)$ & $(15.01)$ & $(31.56)$ & $\{49.26\}$ & $\{50.74\}$ & \\
\hline $2010-11$ & $18,451,000$ & 85922 & 24514 & 56171 & 166607 & 190191 & 356798 \\
\hline & & $(51.57)$ & $(14.71)$ & $(33.71)$ & $\{46.70\}$ & $\{53.30\}$ & \\
\hline $2015-16$ & $21,285,000$ & 103838 & 29227 & 71802 & 204867 & 229106 & 433973 \\
\hline & & $(50.69)$ & $(14.27)$ & $(35.05)$ & $\{47.21\}$ & $\{52.79\}$ & \\
\hline $2020-21$ & $24,485,000$ & 125132 & 34749 & 91012 & 250893 & 263550 & 514443 \\
\hline & & $(49.87)$ & $(13.85)$ & $(36.28)$ & $\{48.77\}$ & $\{51.23\}$ & \\
\hline
\end{tabular}

Note: *Actual data

Note: Figures in parentheses ( ) are percentage of passenger vehicles.

Note: Figures in brackets \{\} are percentage of commercial vehicles.

The total number of commercial vehicles in Delhi will rise from 0.28 million in 2005-06 to 0.51 million in 2020-21. For 2005-06, the share of passenger vehicles to commercial vehicles was less than goods vehicles. However, the projected growth reflects that the share of passenger vehicles is expected to decrease rather than increase to 48.77 percent by the end of 2020-21. Similarly, in the category of passenger vehicles, the share of auto rickshaws will decrease from 53.43 percent in 2005-06 to 49.87 percent in 2020-21. The growth of taxis will be slow, and its share of passenger vehicles will be in a decreasing trend, i.e., 15.01 percent in 200506 to13.85 percent in 2020-21. Interestingly, the number of buses is expected to increase by more than double during the same period (43 thousand in 2005-06 to 91 thousand in 2020-21). As discussed earlier, the logistic and Gompertz models assume different distribution functions for the threshold values of motor vehicle growth. While the logistic function is based on a symmetric frequency distribution, the Gompertz model is derived from a skewed frequency distribution. The distinction has important implications for capacity planners. The results show that the rate of growth in the case of auto rickshaws and taxis is closer to symmetric, as implied by the logistic model, rather than attaining its maximum growth at an 
earlier phase, as the Gompertz model would suggest. Similarly, the reverse situation happens in the growth of buses and goods vehicles. The theoretical model of the logistic and Gompertz curves has been highly effective (Akoi and Yoshikawa 2002), although its empirical results are somewhat less satisfactory for a number of reasons. For example, both the logistic and Gompertz curves are characterized by constantly-declining growth rates after a certain period, but this does not always happen in a real-life situation. In spite of certain limitations, the effectiveness of these curves in theoretical studies led to their application in forecasting the growth of commercial vehicles. This future growth of commercial vehicles will help in estimating diesel demand and the level of sulphur dioxide emissions by the transport sector.

\section{Projection of Diesel Demand}

\section{Growth Pattern in Diesel Consumption}

A diesel engine differs from a petrol engine, mainly in that it relies on heat generated by compressing air in the cylinder to ignite the fuel. To generate the required heat, a diesel engine must produce higher compression than the petrol engine, making it heavier, bulkier, more expensive, and capable of being operated only at slower speeds. But it can operate on cheaper, less highly-refined fuel, which gives it an advantage in many heavy transportation and construction activities. The main users of diesel in commercial vehicles category are taxis, buses, and goods vehicles, which range from light vehicles to heavy bulldozers (Karnik 1989). To overcome some known disadvantages of petrol and diesel engines, basically due to expensive fuel and pollution, the government of Delhi substituted CNG for petrol and diesel fuel as mandatory for the public transport system in Delhi. The order was directed towards replacement of all pre-1990 autos and taxis with new vehicles using clean fuel, and the entire city bus fleet was to be steadily converted to a single fuel mode of CNG by March 31, 2001. CNG is considered to be an environmentally "clean" alternative to diesel and petrol fuels (Transport Department Govt. of NCT of Delhi 2000). Implementation of this directive helped in converting the entire bus fleet and auto rickshaws to CNG engines after 2002-03, whereas, in the case of taxis, the same was done in 2003-04 (Tables 4). 
Table 4. Commercial Vehicles with CNG Engine and CNG Consumption

\begin{tabular}{lccccc}
\hline $\begin{array}{l}\text { Type of } \\
\text { Vehicle }\end{array}$ & $\mathbf{2 0 0 0 - 0 1}$ & $\mathbf{2 0 0 1 - 0 2}$ & $\mathbf{2 0 0 2 - 0 3}$ & $\mathbf{2 0 0 3 - 0 4}$ & $\mathbf{2 0 0 4 - 0 5}$ \\
\hline Auto Rickshaw & 86985 & 86985 & 49538 & 52905 & 53656 \\
& $(22010)$ & $(36565)$ & $(49538)$ & $(52905)$ & $(53656)$ \\
Taxi & 18362 & 20628 & 23145 & 11495 & 13511 \\
& $(2183)$ & $(4569)$ & $(9936)$ & $(11495)$ & $(13511)$ \\
Bus & 41483 & 47578 & 18731 & 21962 & 24235 \\
& $(1982)$ & $(6396)$ & $(18731)$ & $(21962)$ & $(24235)$ \\
CNG in Tons* & 43800 & 129575 & 246375 & 323573 & 336619 \\
\hline
\end{tabular}

Source: Ministry of Petroleum \& Natural Gas, Govt. of India

Note: Figures in parentheses are CNG vehicles converted from total vehicles.

Note: ${ }^{*} 1 \mathrm{Kg}=1.387$ litres

Since 1990-91, the average annual rate of consumption of diesel has been decreasing, while in absolute terms it decreased and attained negative growth rate after 2000-01, as shown in Table 5. The drastic fall in diesel consumption after 2001-02 is due to total conversion of commercial passenger diesel vehicles to CNG engines. At the same time, CNG consumption has increased eight-fold within five years, from 2000-01 to 2004-05, as seen in Table 4.

Table 5. Consumption of Diesel in Delhi

\begin{tabular}{lcccccc}
\hline Years & $\mathbf{1 9 8 0 - 8 1}$ & $\mathbf{1 9 8 5 - 8 6}$ & $\mathbf{1 9 9 0 - 9 1}$ & $\mathbf{1 9 9 5 - 9 6}$ & $\mathbf{2 0 0 0 - 0 1}$ & $\mathbf{2 0 0 4 - 0 5}$ \\
\hline $\begin{array}{l}\text { Diesel } \\
\text { (Tons) }\end{array}$ & \multirow{2}{*}{405000} & 579000 & 798000 & 1198000 & 1301000 & 1272000 \\
& & $(7.23)$ & $(8.67)$ & $(5.66)$ & $(3.00)$ & $-(0.16)$ \\
\hline
\end{tabular}

Source: Statistical Hand Book (various year).

Note: Figures in the parentheses are average growth rate of five years.

\section{Diesel Demand Estimation}

The demand for diesel energy is derived from the demand for diesel vehicles, which is well established by many studies (Karnik 1989; Banaszak et al. 1999). To establish a functional relationship with respect to diesel demand, it was attempted to consider the growth of diesel taxis (DT), diesel buses, and goods vehicles (DBGV) as explanatory variables. Buses and goods vehicles are combined because both contain light to heavy vehicles with proportionately the same fuel efficiency. This relationship is set up in the form of log linear multiple regressions. The forecast of diesel demand is obtained by assuming various scenarios for the future growth 
of the explanatory variables. Using available data from 1980-81 to 2004-05, the In Diesel (equation [12]) estimate the diesel demand as given below, where figures in parentheses are values of $t$ statistics.

$$
\text { In Diesel }=4.0003+0.0244 \times 1 \mathrm{n} D T+0.8443 \times 1 \mathrm{n} D B G V
$$

$$
\mathrm{R}^{2}=0.94, D W=1.61
$$

From equation (12), it is observed that the estimated DW for In Diesel is found to be 1.61, which falls in the range of no autocorrelation, i.e., between 1.55 and 2.45 (Makridakis et al.1998). As per Klein's rule of thumb, the model is also free from multicolinearity problem (Klien 1962). Hence, the data fit well for estimating the diesel demand in Delhi. The $t$ statistics of all the parameters in the In Diesel model is significant at the $95 \%$ confidence level. Similarly, $R^{2}$, the coefficient of determination of In Diesel model, is 0.94 , indicating that all included variables account for 94 percent of the original variation in the response variable, while the remaining 6 percent represents the variation of residuals. Therefore, the determinants explaining diesel demand are highly significant. From the coefficient of determinants, it is observed that the growth of diesel buses and goods vehicles has significantly more influence on diesel demand than diesel taxis. It is also observed from In Diesel that the changes in the growth of a unit of diesel buses and goods vehicles change the demand of diesel by 0.84 units, provided other things remain constant. However, in the case of taxis, it is very low ( 0.02 units). This is basically due to the slow growth and gradual conversion of diesel taxis to CNG engines. Therefore, using diesel goods vehicles data from Table 3, the In Diesel model projects the demand of diesel for the years 2010-11, 2015-16, and 2020-21 under different scenarios (Figure 5).

S1 is the "as usual" scenario, which estimates the diesel demand under "as usual" growth of diesel vehicles. In this scenario, the demand for diesel will increase more than 100 percent by 2020-21, as compared to the year 2005-06. On the other hand, scenario S2 estimates the diesel demand under 5,10 , and 25 percent conversion of diesel goods vehicles to CNG engines in the years 2010-11, 2015-16, and 202021. The above conversion of diesel goods vehicles will reduce diesel demand by 4 , 9 , and 22 percent from that of the demand for diesel under $\$ 1$ in the respective years. 


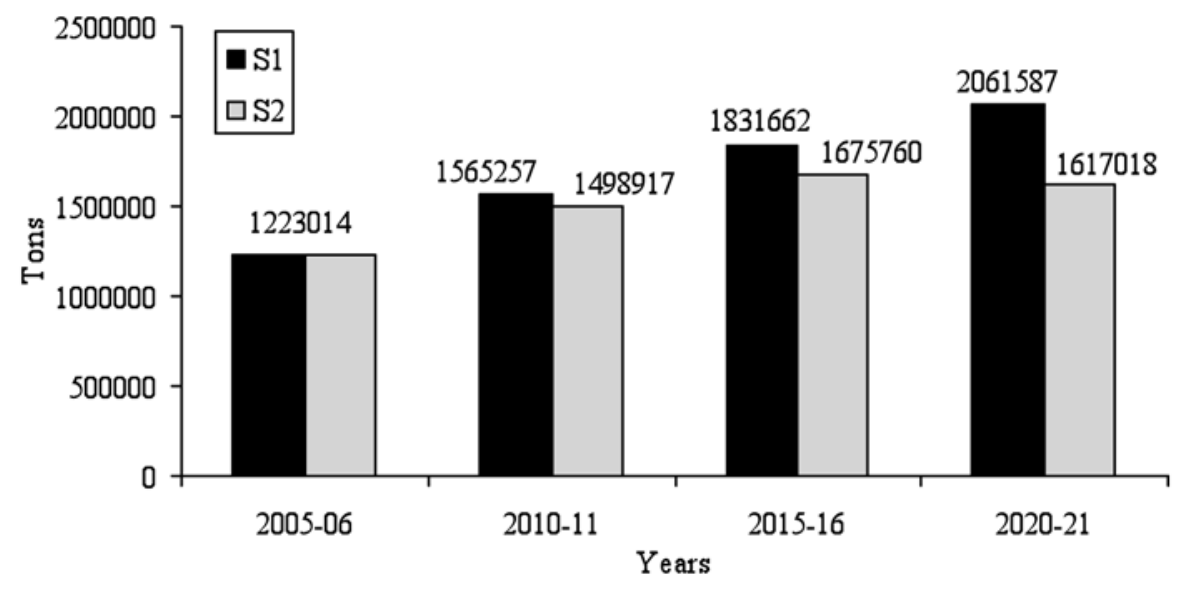

Figure 5. Projected Diesel Demand in Delhi

\section{Projection of Sulphur Dioxide Emission}

\section{Growth Pattern in Sulphur Dioxide Emissions}

Sulphur dioxide $\left(\mathrm{SO}_{2}\right)$ is one of the principal constituents of vehicular pollutants. The main source of sulphur dioxide is the combustion of sulphur contained in fuel, especially in diesel-powered vehicles. Sulphur dioxide is a colourless, soluble gas with a characteristic pungent smell, which forms sulphuric acid when combined with water. It is an irritant gas and, when inhaled, affects mucous membranes and causes oxygen deficiency in the body. Persons with asthma are badly affected by this pollutant (Rao and Rao 2001). The highest percentage of sulphur dioxide is exhausted by a diesel engine (Bose 1998; Reddy et al. 2000; Rao and Rao 2001). The period between 1990-91 and 1995-96 saw a rapid increase in the $\mathrm{SO}_{2}$ pollutant level in the air of Delhi (Table 6). This may be due to the significant growth in diesel vehicles and diesel consumption over the last two decades, which can also be seen in Table 1 and Table 5.

Table 6. Annual Average Concentration of Sulphur Dioxide in Delhi (in $\mu \mathrm{g} / \mathrm{m} 3$ )

\begin{tabular}{lcccc}
\hline Year & $\mathbf{1 9 9 0 - 9 1}$ & $\mathbf{1 9 9 5 - 9 6}$ & $\mathbf{2 0 0 0 - 0 1}$ & $\mathbf{2 0 0 5 - 0 6}$ \\
\hline $\mathrm{SO}_{2}$ & 11.65 & 20.50 & 18.03 & 8.83 \\
& & $(17.63)$ & $-(1.77)$ & $-(14.19)$ \\
\hline
\end{tabular}

Source: Economic Survey Delhi, 2005-06

Note: Figures in parentheses are average five years annual growth rate. 
On the other hand, the annual average $\mathrm{SO}_{2}$ level has gradually been decreasing from $20.50 \mathrm{mg} / \mathrm{m} 3$ in $1995-96$ to $8.83 \mathrm{mg} / \mathrm{m} 3$ in 2005-06 (Table 6). This could be attributed to the stringent implementation of vehicular emission norms, fuel quality upgrading, and better maintenance of engines through all possible measures. This tremendous achievement could also be linked to the conversion of commercial passenger vehicles to CNG engines (Table 4). However, during this period, goods vehicles have increased from 0.1 million to 0.14 million (Table 1), an increase of about 40 percent within a period of 15 years. From Table 5 , it can be observed that diesel consumption has increased from 798 thousand tons in 1990-91 to 1,272 thousand tons in 2004-05, an increase of 62.73 percent. This has resulted in the corresponding level of $\mathrm{SO}_{2}$ pollutants.

\section{$\mathrm{SO}_{2}$ Emission Estimation}

The relationship between $\mathrm{SO}_{2}$ emissions and their source, the growth of diesel vehicles, is established by linear regression model (Khare and Sharma 2002) in this section. Starting from 1990-91 to 2005-06, 16 annual observations of average $\mathrm{SO}_{2}$ pollutant levels have been taken from the Economic Survey Delhi 2003-04 and 2005-06. The responsibility of data collection rests on the Central Pollution Control Board, which monitors air quality at various locations in Delhi. The monitoring stations are located at Ashok Vihar, Shahzadabagh, Siri Fort, Janakpuri, Nizamuddin, and Shahdara.I Initially, monitoring was for 8 hours, but was subsequently extended to 24 hours from 1994 onwards. Data for the sulphur content in diesel was taken from www.dieselnet.com/standards/in/fuel.html. Using data for diesel consumption (DC), diesel vehicles (DV), and sulphur content in diesel (S), the estimated $\mathrm{SO}_{2}$ emission model is presented. (Figures in parentheses are values of t statistics.)

$$
S_{2}=-15.81+0.000012 D C+0.000071 D V+11.85 \mathrm{~S}
$$

$$
R_{2}=0.74, D W=1.15
$$

From equation (13), it can be observed that the estimated DW for $\mathrm{SO}_{2}$ is found to be 1.15, which falls into an inconclusive range, between 0.9 and 1.71 (Makridakis et al. 1998). As per Klein's rule of thumb, the model is also free from the multicolinearity problem (Klien 1962). The $t$ statistics of all the explanatory variables in $\mathrm{SO}_{2}$ models are significant at the $95 \%$ confidence level, except the variable of diesel consumption, which is significant at the $90 \%$ confidence level. Therefore, the 
values of the coefficients are consistent with the physical effect of the respective variables. The coefficient of the growth of diesel consumption, diesel vehicles, and sulphur content is of the expected sign in accordance with the fact that it is highly correlated with $\mathrm{SO}_{2}$ concentration. Therefore, the growth of diesel consumption, diesel vehicles, and sulphur content in diesel are directly proportional to the growth of $\mathrm{SO}_{2}$ concentration. This implies that the increase or decrease in $\mathrm{SO}_{2}$ concentration depends upon the increase or decrease in the growth of diesel vehicles, diesel consumption, and sulphur content in diesel. From the coefficient of the explanatory variable in the $\mathrm{SO}_{2}$ model, it is observed that the sulphur content in diesel influences more on $\mathrm{SO}_{2}$ concentration than diesel consumption and diesel vehicles. Finally, the coefficient of determination $R_{2}$ for the $\mathrm{SO}_{2}$ model is equal to 0.74 (equation [13]), indicating that all included variables account for 74 percent of the original variation in the response variable, while the remaining 26 percent represents the variation of the residuals. The diagnostic check of predictor variables suggests that the growth of diesel vehicles, diesel consumption, and sulphur content should be included, as it is capable of fitting the data satisfactorily. Using the future growth of diesel vehicles and diesel consumption from Table 3 and 4, the $\mathrm{SO}_{2}$ model projects the future level of $\mathrm{SO}_{2}$ pollutant for the years 2010, 2015, and 2020 under different scenarios in Delhi (Figure 6).

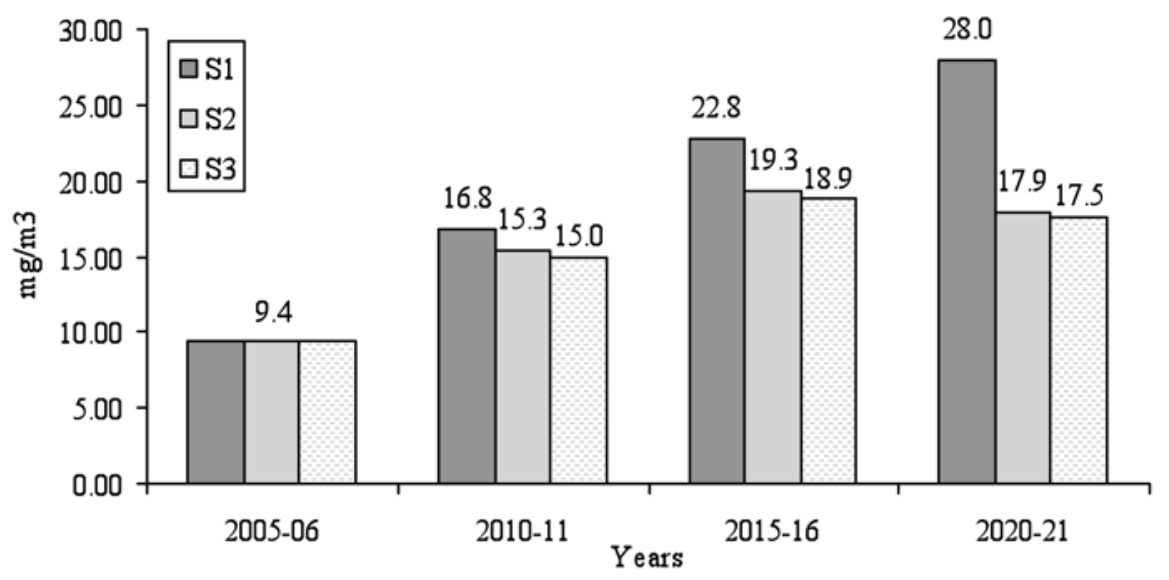

Figure 6. Projected Sulphur Dioxide Level in Delhi

$\mathrm{S} 1$ is the "as usual" scenario, which estimates the concentration of $\mathrm{SO}_{2}$ pollutant under "as usual" growth of diesel vehicles, diesel consumption, and 0.035 percent of sulphur content in diesel. In this scenario, the concentration of $\mathrm{SO}_{2}$ pollutant 
will increase by nearly five times by the year 2020-21 as compared to the level of 2005-06. Similarly, scenario S2 estimates the concentration of $\mathrm{SO}_{2}$ under scenario S1 with the additional constraint of 5,10 , and 25 percent of goods vehicles converted to CNG in 2010-11, 2015-16, and 2020-21, respectively. The above percentage of conversion will reduce the concentration of $\mathrm{SO}_{2}$ levels from 9 to 35 percent during the same period. Finally, scenario $\mathrm{S} 3$ estimates $\mathrm{SO}_{2}$ levels under the $\mathrm{S} 2$ scenario with a reduction of sulphur content from 0.005 to 0.001 percent in diesel fuel during the period from 2010-11 to 2020-21. This reduction of sulphur content will further reduce the concentration of $\mathrm{SO} 2$ levels from 11 to 37 percent, as can be seen in Figure 6.

\section{Strategies to Reduce Diesel Demand and $\mathrm{SO}_{2}$ Emission}

The transport sector is one of the fastest-growing sectors in terms of energy consumption and air pollution, not only in Delhi but also in many other cities. In this sector, the growth of commercial vehicles plays a significant role, leading to higher diesel consumption and $\mathrm{SO}_{2}$ emission. The demand for more diesel energy for transportation leads to its scarcity and increases the cost of importing. On the other hand, $\mathrm{SO}_{2}$ emissions in urban areas affect the health of humans, animals, and plants. Due to the depleting and polluting nature of diesel energy, reduction measures may be taken in the following manner. The rail transport system depends on electric energy in most Indian cities. Therefore, it has lower external costs than road transport in relation to energy consumption. Although rail-based transport services in Delhi are available for intra-city transportation, they play very little role in meeting the travel demand of city people. In 2005-06, Delhi opened its first phase of the Metro rail network for passenger transport. In our study, it was observed that the introduction of Metro rail has marginally reduced the use of road-based passenger vehicles on parallel routes. Considering the financial health of the government and the investment required to increase the rail (Metro) based passenger transport system, it is also evident that bus transport services in Delhi will have to play a major role in providing passenger transport services in future. Therefore, there is an urgent need for the restructuring of the bus transit system in Delhi to enhance both quantity and quality of services. There is a need for an integrated rail and road-based public transport system in Delhi, which would have the potential to attract people towards the public transport system. There should be offer of an attractive and easier way to use the public transport system, leading to the use of existing resources with improvements in the efficiency of 
service delivery and comfort for commuters. On the other hand, the government should encourage goods vehicles to use cleaner fuel such as CNG which, in turn, will reduce diesel demand and $\mathrm{SO}_{2}$ emissions in future. Therefore, strengthening the public transport system, especially rail, promoting cleaner fuel and improved engine technologies, and reducing sulphur content in diesel can reduce diesel demand and sulphur emissions in Delhi considerably.

\section{Conclusion}

This study estimates the future growth of commercial vehicles in the road transport sector and corresponding diesel demand and $\mathrm{SO}_{2}$ emissions in Delhi. A simple observation of trends over the past 41 years clearly shows a significant increase in the growth of commercial vehicles. The total number of commercial vehicles will increase from 0.28 million in 2005-06 to 0.51 million in 2020-21, with almost equal shares of passenger and goods vehicles. This growth of commercial vehicles will demand 50 percent more diesel fuel in 2020-21 as compared to the year 2004-05, which leads to an increase in $\mathrm{SO}_{2}$ levels by nearly three times. However, significant reductionswill be possible under a higher rate of conversion in diesel goods vehicles to CNG engines. Therefore, the government should encourage goods vehicles to use cleaner alternative fuel such as CNG for the reduction of diesel demand and sulphur emissions. There is a need for an integrated rail and road-based public transport system in Delhi, which will have the potential to attract people towards the public transport system.

\section{References}

Akoi, M., and Yoshikawa, H. 2002. Demand saturation creation and economic growth. Journal of Economic Behavior and Organization 48: 127-154

Banaszak S., U. Chakravorty, and P. Leung. 1999. Demand for ground transportation fuel and pricing policy in Asian tigers: A comparative study of Korea and Taiwan. The Energy Journal 20(2): 145-165

Bose R. K. 1998. Automotive energy use and emissions control: A simulation model to analyse transport strategies for Indian metros. Energy Policy 26(13): 10011016

Button, K., N. Ngoe, and J. L. Hine. 1993. Modeling vehicle ownership and use in low income countries. Journal of Transport Economics and Policy 27(1): 51-67 
Das, D. 2008. Transportation systems in Delhi: A modeling approach. Unpublished thesis, Jamia Millia Islamia, Central University, New Delhi, India.

Das, D., A. Sharfuddin, and S. Datta. 2009. Personal vehicles in Delhi: Petrol demand and carbon emission. International Journal of Sustainable Transportation 3 (2): 122-137

Delhi Pollution Control Committee, Govt. of NCT of Delhi. 2003. Towards cleaner air: A case study of Delhi.

Directorate of Economic and Statistics, Government of NCT of Delhi, New Delhi. Delhi Statistical Handbook. Various issues.

Draper, N. R., H. Smith. 1998. Applied Regression Analysis. John Wiley \& Sons Inc., Singapore

Indian National Academy of Engineering, New Delhi. 1996. Urban Transportation in India. Allied Publishers Limited, New Delhi.

Jarnc, G., J. Sanchez-Choliz, and F. Fatas-Villafranca. 2005. "S-shape" economic dynamics: The kogistic amd Gompertz curves generalized. The Electronic Journal of Evolutionary Modeling and Economic Dynamics. 1048: 1-37. www.ejemed.org

Karnik, A. V. 1989. Energy in Indian Transportation-The Emerging Scenario. Himalaya Publishing House, Bombay, India

Kathuria, V. 2002. Vehicular pollution control in Delhi, India: Are the efforts enough? Transport Research: Part D. 7(5): 373-387

Khare, M., and P. Sharma. 2002. Modeling Urban Vehicle Emissions. WIT PRESS, Southampton, Boston.

Klien, L. R. 1962. An Introduction to Econometrics. Prentice-Hall Englewood Cliffs. New Jursey.

Makridakis, S., S. C. Wheelwright, and R. J. Hyndman. 1998. Forecasting Methods and Application. John Wiley \& Sons Inc. Singapore

Ogut, K. S. 2004. S-curve models to determine the car ownership in Turkey. ARI 54 (2): 65-69

Palelink, J. 1960. Projection du parc Automobile en Belgique. Cashiess Economiques de Bruxellers 3: 407-418 
Pelsmacker, D. E. P. 1990. A structural model of the demand for new cars in Belgium. Applied Economics 22: 669-686

Peter, H. K., D.E. Jon, and E. D. Thomas. 2003. Scenario analysis of Chinese passenger vehicle growth. Contemporary Economic Policy 21(2): 200-217

Planning Department Government of NCT of Delhi, New Delhi. Economic Survey of Delhi. 2003-04, 2005-06 and 2007-08.

Prescott, R. B. 1922. Law of growth in forecasting demand. Journal of American Statistical Association 471-479

Rao, M.N., and H. V. N. Rao. 2001. Air Pollution. Tata McGraw Hill Publishing Company limited, New Delhi.

Reddy, A. K. N., Y. P. Anand, and A. D'Sa. 2000. Energy for a sustainable road/rail transport system in India. Energy for Sustainable Development 4(1): 29-44

Singh, S. K. 2000. Estimating the level of rail and road based passenger mobility in India. Indian Journal of Transport Management 24(12): 771-781

Singh, S. K. 2006. The demand for road-based passenger mobility in India: 19502030 and relevance for developing and developed countries. European Journal of Transport and Infrastructure Research 6(3): 247-274

Smith, D., and N. Keyfitz. 1977. Mathematical Demography. Springer Verlag

Tanner, J. C. 1978. Long term forecasting of vehicle ownership and road traffic. Journal of the Royal Statistical Society 141(A): 14-63

Tarde, G. 1903. The Laws of Imitation. Henry Holt. (Translation into English of Le lois de l' imitation, 1890).

Transport Department Govt. of NCT of Delhi, India. 2000. Directions of Hon'ble Supreme Court for control of pollution in Delhi, 2000. http://transport.delhigovt.nic.in / pc /pc.html.

\section{About the Author}

Dr. Debabrata Das (debabrata69@hotmail.com) has over 13 years of teaching and research experience in the area of Quantitative Technique and Business Research. He holds a postgraduate degree in mathematics and Ph.D. degree on Urban Transportation Systems. He has several publications in refereed journals in different countries and has conducted a number of long-term sponsored research 
projects for the government as well as the corporate sector in the areas of rural development, knowledge management, employee satisfaction, operations and production. His research interests are transportation, energy and environment, and socioeconomic and marketing research. 